\title{
A social work study on the relationship between personality traits, prestige sensitivity, and fashion consciousness of Iranian students
}

\author{
Mohammad Reza Iravani $^{a^{*}}$, Kazem Ghojavand ${ }^{a}$, Faezeh Taghipour ${ }^{b}$ and Yosef Masomi ${ }^{\mathrm{c}}$
}

${ }^{a}$ Assistant Professor, Department of Social Work, Islamic Azad University, Khomeinishahr Branch, Daneshjou Blvd, Isfahan, Iran
${ }^{b}$ Assistant Professor, Department of Cultural Management Khorasgan (Isfahan) Branch, Islamic Azad University, Isfahan, Iran
${ }^{c}$ Department of Cultural Management Khorasgan (Isfahan) Branch, Islamic Azad University, Isfahan, Iran

\begin{tabular}{|c|c|}
\hline A R T I C L E I N F O & A B S T R A C T \\
\hline $\begin{array}{l}\text { Article history: } \\
\text { Received June 20, } 2012 \\
\text { Received in Revised form } \\
\text { August, 20, } 2012 \\
\text { Accepted } 25 \text { August } 2012 \\
\text { Available online } \\
1 \text { September } 2012 \\
\text { Keywords: } \\
\text { Fashion } \\
\text { University student } \\
\text { Life style }\end{array}$ & $\begin{array}{l}\text { Fashion plays an important role on lifestyle and many people spend their money proportion to } \\
\text { fashion changes. In this paper, we present an empirical study among students who attend some } \\
\text { private schools in Iran. The study investigates whether there is any correlation between fashion } \\
\text { consciousness as well as fashion practices and national identity, university student gender and } \\
\text { mass media. The proposed study designs a questionnaire and distributes among } 384 \text { students } \\
\text { who attend university and analyze the results using Pearson correlation test. The results indicate } \\
\text { that there is a positive correlation between national consciousness and fashion, a positive } \\
\text { correlation between using mass media applications and fashion. However, the results of the } \\
\text { study do not indicate any significance correlation between fashion and mixture of students in } \\
\text { terms of gender. }\end{array}$ \\
\hline
\end{tabular}

(C) 2012 Growing Science Ltd. All rights reserved.

\section{Introduction}

Fashion plays an important role on people's capital spending and life style. Fashion consciousness could impact people to change people's habit and make different changes on people's belongings such as home furnture, appliances, dress, etc. (Back, 1985; Bakewell et al., 2006). Muzinich et al. (2003) presented an empirical study on a causal model of female fashion innovativeness by building the value of a domain-specific fashion innovator construct, identifies the key determinants and consequents of female fashion innovativeness. They study examined these relationships on data collected from a sample of female respondents using partial least squares. They reported the predicted relationships recommending that the model could provide a reasonable framework to understand female fashion innovativeness. Underestanding life style also plays an essential role on market investigation.

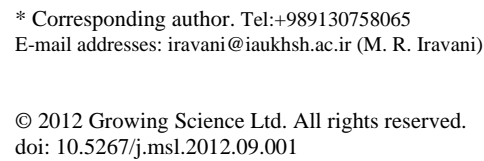


Hubacek et al. (2009) investigated lifestyle changes and other important socio-economic trends in China. They investigated implications of these changes for Beijing and compared with China for the year 2020. van Eijck and Bargeman (2004) investigated a number of hypotheses on the changing impats of social background on cultural consumption. They reported a decrease in the imapcts of age, gender, education, income, religion, and political party preference on popular cultural activities.

The growth of fashion industry in recent years could be contributed to consumers' changing habitts towards fashion. Consumers are becoming more fashion-conscious and keeping themselves updated with the latest fashion trends (D’Aveni, 2010). Casidy (2012) performed an empirical investigation of the relationship between personality traits, prestige sensitivity, and fashion consciousness of Generation Y in Australia. He reported that certain personality traits were substantially associated with fashion consciousness and prestige sensitivity. The report also disclosed that fashion consciousness performed a mediating impact in the relationship between personality traits and prestige sensitivity. Personality traits were reported to perform an important imapct in affecting people's attitude towards prestige fashion brands. The report stated that it was necessary for marketers to understand the impact of certain personality traits on fashion consciousness and prestige sensitivity to enhance the effectiveness of brand appeals. The study also investiagted the scope of personality research in marketing by utilising the Big Five construct to study the phenomenon of fashion consciousness and prestige sensitivity among Gen Y consumers.

Lertwannawit and Mandhachitara (2012) performed another investigation on interpersonal impacts on fashion consciousness and status consumption moderated by materialism in metropolitan men. They performed a path analysis, which demonstrated that indirect impact could provide indept insight into the impacts of interpersonal factors on status consumption. Besides, high and low materialism serve as moderating forces in the relationship between fashion consciousness and status consumption, producing various impacts. In the high-materialism group, susceptibility to interpersonal impact alone had an indirect influence via fashion consciousness on status consumption, whereas the lowmaterialism group needed self-monitoring as an additional antecedent of status consumption.

Li et al. (2012) studied Chinese consumers' attitudes to pay for luxury fashion brands associated with their fashion lifestyle and perceived value. Practicality fashion lifestyle, perceived social/emotional value, perceived utilitarian value, and perceived economic value were detected to maintain a substantial impact on the willingness of Chinese consumers to spend for luxury fashion brands in a multiple regression model. This research also investigated various impacts of fashion lifestyles and perceived value on willingness to spend among four groups characterized by various previous genuine and counterfeit purchasing experiences.

In this paper, we present an empirical study on relationship between fashion consciousnesses of Iranian students who attend private universities in Iran. The organization of this paper presents problem statement in section 2. Section 3 presents details of our results and finally concluding remarks are given in the last to summarize the contribution of the paper.

\section{The problem statement}

The proposed study of this paper examines three hypotheses as follows,

1. There is a positive and meaningful relationship between economical factors and fashion consciousnesses.

2. There is a positive and meaningful relationship between cultural factors and fashion consciousnesses.

3. There is a positive and meaningful relationship between social factors and fashion consciousnesses. 
Fig. 1 shows details of our proposed model.

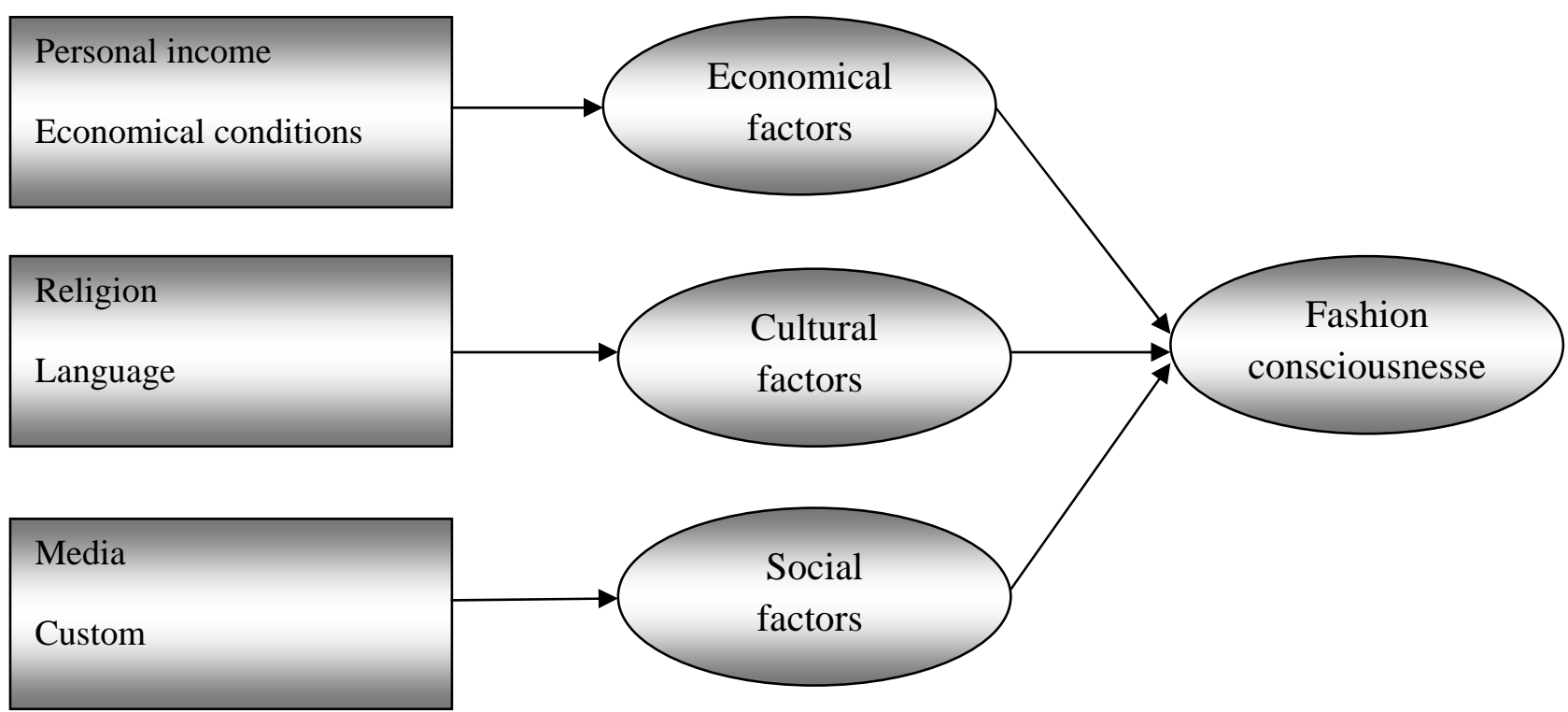

Fig. 1. Framework of the proposed study

We use the following formula to calculate the minimum number of sample size,

$n=\frac{N \times z_{\alpha / 2}^{2} \times p \times q}{\varepsilon^{2} \times(N-1)+z_{\alpha / 2}^{2} \times p \times q}$,

where $N$ is the population size, $p=1-q$ represents the yes/no categories, $z_{\alpha / 2}$ is CDF of normal distribution and finally $\varepsilon$ is the error term. Since we have $p=0.5, z_{\alpha / 2}=1.96$ and $N=4760$, the number of sample size is calculated as $n=384$. We have distributed the questionnaire among 10 sample students and calcualted Cronbach alpha, which yielded 0.83 , which is well above the minimum acceptable level of 0.70 .

\subsection{Personal characteristics}

In this section, we present some of the personal characteristics of the people who participated in our survey. Table 1 shows details of their participants in terms of their age.

\section{Table 1}

Personal characterisics

\begin{tabular}{llllll}
\hline Age & $18-22$ & $23-26$ & $27-30$ & $>31$ & Total \\
\hline Frequencies & 203 & 118 & 27 & 27 & 375 \\
Percentage & 54.1 & 31.5 & 7.2 & 7.2 & 100.0 \\
\hline Education & 12 years & 14 years & 16 years & 18 years & Total \\
\hline Frequencies & 50 & 25 & 277 & 24 & 375 \\
Percentage & 13.3 & 6.6 & 73.7 & 6.4 & 100.0 \\
\hline Salary(Per month) & $<200 \$$ & $200 \$-500 \$$ & $500 \$-800 \$$ & $>800$ & Total \\
\hline Frequencies & 11 & 59 & 99 & 187 & 375 \\
Percentage & 3.1 & 16.6 & 27.8 & 52.3 & 100.0 \\
\hline
\end{tabular}

As we can observe from the results of Table 1, over half of the people who took part in our survey were young. In terms of the number of family members, most of them had more than three brothers and sisters and in terms of marital status, $29.3 \%$ of the participants were single and the remaining $70.2 \%$ were married. Based on the survey results given in Table $1,73.7 \%$ of the participants hold a bachelor degree of science, which means people are highly educated. In terms of their job status, 
$84.3 \%$ of the people who took part in this survey had no job and only $15.7 \%$ were employed. In terms of their salary, over half of the participants' parents earned more than $800 \$$ per month, which is considered a good salary in Iran for the period of study. However, nearly $83.6 \%$ of the participants relied on their parents' pocket money and had no personal income.

\subsection{Media entertainment}

Media entertainments including national Television, internet or satellite TV are some of the most important factors influencing fashion awareness. Table 2 shows details of entertainment use among the participants of this survey.

Table 2

The level of entertainment use including national TV, internet and satellite

\begin{tabular}{lcccccc}
\hline National TV & Very little & Low & Average & Much & Very much & Total \\
\hline Frequencies & 66 & 65 & 118 & 73 & 53 & 375 \\
Percentage & 17.6 & 17.3 & 31.5 & 19.5 & 14.1 & 100.0 \\
\hline Internet & Very little & Low & Average & Much & Very much & Total \\
\hline Frequencies & 164 & 110 & 60 & 29 & 15 & 375 \\
Percentage & 43.4 & 29.1 & 15.9 & 7.7 & 4 & 100.0 \\
\hline Satellite TV & Very little & Low & Average & Much & Very much & Total \\
\hline Frequencies & 107 & 77 & 87 & 62 & 44 & 375 \\
Percentage & 28.4 & 20.4 & 23.1 & 16.4 & 11.7 & 100.0 \\
\hline
\end{tabular}

As we can observe from the results of Table 2, people spend less time on internet compared with national or satellite TV since $43.4 \%$ of the participants believed they spent very little on internet while only $17.6 \%$ believed they spent very little on national TV and $28.4 \%$ also indicated they spent very little on satellite TV. Over 64\% of the participants indicated that they spent above average on national or satellite TV, which means they may be influenced more by TV.

\section{The results}

In this section, we present details of our finding concerning three questions of the survey including the effects of economy, culture and social on fashion.

\subsection{Economy and fashion}

The first hypothesis is associated with the impact of economical factors on fashion consciousness. Pearson correlation test yields 4310 with 379 degree of freedom and P-value of 0.000 , which means we can reject the null hypothesis when the level of significance is five percent and conclude that economical conditions significantly impact on fashion and life style among students who participated in our survey. The ratio of $\mathrm{r}^{2}=0.185$, which means economy could describe approximately $19 \%$ of fashion oriented requirements.

\subsubsection{The relationship between family income and fashion}

To test the first sub-hypothesis, we use Spearman test, which yields 0.187 with 379 degree of freedom and P-value of 0.02 . Therefore, we can statistically specify that there is positive correlation between family income and fashion consciousness. The ratio of $r^{2}=0.034$, which means family income could describe approximately $3.4 \%$ of fashion oriented requirements.

\subsubsection{The relationship between personal job status and fashion}

To test the second sub-hypothesis, we use Spearman test, which yields -0.29 with 379 degree of freedom and P-value of 0.584. Therefore, we cannot statistically specify that there is meaningful relationship between job status and fashion consciousness. 


\subsubsection{The relationship between access to supportive equipments and fashion}

To test the third sub-hypothesis, we use Spearman test, which yields 0.259 with 379 degree of freedom and P-value of 0.000 . Therefore, we cannot statistically specify that there is meaningful relationship between supportive equipment such as car, mobile phone, etc. and fashion consciousness. The ratio of $r^{2}=0.067$, which means having access to supportive equipment such as car, mobile, etc. could describe approximately $6.7 \%$ of fashion oriented requirements.

\subsection{Culture and fashion}

The second hypothesis is associated with the impact of cultural factors on fashion consciousness. Pearson correlation test yields 7130 with 379 degree of freedom and P-value of 0.000 , which means we can reject the null hypothesis when the level of significance is five percent and conclude that cultural conditions substantially impact on fashion and life style among students who participated in our survey. The ratio of $r^{2}=0.508$, which means culture could describe approximately $51 \%$ of fashion oriented requirements.

\subsubsection{The relationship between mass media and fashion}

To test the first sub-hypothesis, we use Spearman test, which yields 0.353 with 379 degree of freedom and P-value of 0.000 . Therefore, we can statistically specify that there is a meaningful relationship between mass media and fashion consciousness. The ratio of $\mathrm{r}^{2}=0.124$, which means having access to mass media such as national TV, internet or Satellite could describe approximately $12.4 \%$ of fashion oriented requirements.

\subsubsection{The relationship between religious beliefs and fashion}

To test the second sub-hypothesis, we use Spearman test, which yields 0.658 with 379 degree of freedom and P-value of 0.000 . Therefore, we can statistically specify that there is a meaningful relationship between religious beliefs and fashion consciousness. The ratio of $\mathrm{r}^{2}=0.432$, which means religious beliefs could describe approximately $43.2 \%$ of fashion oriented requirements.

\subsubsection{The relationship between national identity and fashion}

To test the third sub-hypothesis, we use Spearman test, which yields 0.353 with 379 degree of freedom and P-value of 0.000 . Therefore, we can statistically specify that there is a meaningful relationship between national identity and fashion consciousness. The ratio of $\mathrm{r}^{2}=0.124$, which means national identity could describe approximately $12.4 \%$ of fashion oriented requirements.

\subsubsection{The relationship between extracurricular activities and fashion}

To test the fourth sub-hypothesis, we use Spearman test, which yields 0.588 with 379 degree of freedom and P-value of 0.000 . Therefore, we can statistically specify that there is a meaningful relationship between national identity and fashion consciousness. The ratio of $r^{2}=0.346$, which means extracurricular activities could describe approximately $34.6 \%$ of fashion oriented requirements.

\subsection{Social factors and fashion}

Finally, the third hypothesis is associated with the impact of cultural factors on fashion consciousness. Pearson correlation test yields 6770 with 379 degree of freedom and P-value of 0.000, which means we can reject the null hypothesis when the level of significance is five percent and conclude that social conditions substantially impact on fashion and life style among students who participated in our survey. The ratio of $\mathrm{r}^{2}=0.458$, which means social factors could describe approximately $46 \%$ of fashion oriented requirements. 


\subsubsection{The relationship between mixed classes and fashion}

To test the first sub-hypothesis, we use Spearman test, which yields 0.953 with 379 degree of freedom and P-value of 0.329. Therefore, we cannot statistically specify that there is any meaningful relationship between mixed classes, male and female students, and fashion consciousness.

\subsubsection{The relationship between following peer and fashion}

To test the second sub-hypothesis, we use Spearman test, which yields 0.463 with 379 degree of freedom and P-value of 0.000 . Therefore, we can statistically specify that there is a meaningful relationship between following peer and fashion consciousness.

\section{Conclusion}

In this paper, we have presented an empirical study to find the effect of different economical, cultural and social factors on fashion. The proposed study distributed 384 questionnaires among female students who participated in some private universities in Iran. The results indicated that there was a strong and positive correlation between economical, cultural and social conditions and fashion. However, the survey results indicated that there was no correlation between mixed classes and fashion. In other words, it does not create any change whether in classes, there are both female and male or only female students attend classes. The other observation is that most people follow others, which means when someone follows a particular fashion, others may also follow that person.

\section{Acknowledgment}

The authors would like to thank anonymous referees for constructive comments on earlier version of this paper.

\section{References}

Back, K.W. (1985). Modernism and fashion: A social psychological interpretation. Lexington, MA: Lexington Books.

Bakewell, C., Mitchell, V.W., \& Rothwell, M. (2006). UK generation Y male fashion consciousness. Journal of Fashion Marketing and Management, 10(2), 169-80.

Casidy, R. (2012). An empirical investigation of the relationship between personality traits, prestige sensitivity, and fashion consciousness of Generation Y in Australia. Australasian Marketing Journal, doi: 10.1016/j.ausmj.2012.05.012.

Cronbach, L. J. (1951). Coefficient alpha and the internal structure of tests. Psychometrika, 16(3), 297-334.

D'aveni, R. (2010). Fashion conscious: Lessons in commoditization from the fashion industry. Ivey Business Journal, 74 (2), 1-4.

Hubacek, K., Guan, D., Barrett, J., \& Wiedmann, T. (2009). Environmental implications of urbanization and lifestyle change in China: Ecological and Water Footprints. Journal of Cleaner Production, 17(14), 1241-1248.

Lertwannawit, A., \& Mandhachitara, R. (2012). Interpersonal effects on fashion consciousness and status consumption moderated by materialism in metropolitan men. Journal of Business Research, 65(10), 1408-1416.

Li, G., Li, G., \& Kambele, Z. (2012). Luxury fashion brand consumers in China: Perceived value, fashion lifestyle, and willingness to pay. Journal of Business Research, 65(10), 1516-1522.

Muzinich, N., Pecotich, A., \& Putrevu, S. (2003). A model of the antecedents and consequents of female fashion innovativeness. Journal of Retailing and Consumer Services, 10(5), 297-310.

van Eijck, K., \& Bargeman, B. (2004). The changing impact of social background on lifestyle: “culturalization” instead of individualization? Poetics, 32(6), 447-469. 